\title{
JURISDIÇÃO CONSTITUCIONAL: UMA EVOLUÇÃO OU UM EXPANSIONISMO DO PODER JUDICIÁRIO?
}

\author{
Paula Constantino Chagas Lessa ${ }^{1}$
}

\section{RESUMO}

Traça-se um breve histórico do controle de constitucionalidade através dos Tribunais Constitucionais, estruturados principalmente para conter deturpações inerentes ao sistema democrático e impedir abusos do poder estatal frente aos direitos individuais de seus cidadãos. Revela-se o fortalecimento do papel do Supremo Tribunal Federal (STF) no regime democrático brasileiro após a Constituição Federal de 1988 e os questionamentos que surgem de sua atuação. Discutindo, se as decisões judiciais fazem parte de um crescente ativismo judicial e, deste modo, ameaçariam a legitimidade democrática, ou se suprem lacunas deixadas pelo legislador ordinário em prol da cidadania.

Palavras-Chave: Controle de constitucionalidade. Ativismo judicial. Minimalismo judicial. Lacunas legais. Equilíbrio de poderes.

\section{CONSTITUTIONAL JURISDICTION: AN EVOLUTION OR AN EXPANSIONISM OF JUDICIAL POWER?}

\section{ABSTRACT}

A brief history of the constitutionality control through the Constitutional Courts is outlined, mainly structured to contain distortions inherent to the democratic system and to prevent abuses of state power against the individual rights of its citizens. It reveals the strengthening of the role of the Supreme Court (STF) in the Brazilian democratic regime after the Federal Constitution of 1988 and the questions that arise from its performance. Arguing, whether judicial decisions are part of a growing judicial activism and, in this way, would threaten democratic legitimacy, or if they fill gaps left by the ordinary legislator in favor of citizenship.

KEY-WORDS: Constitutionality control. Judicial activism. Judicial minimalism. Legal loopholes. Balance between powers.

\section{INTRODUÇÃO}

A partir do final da Segunda Guerra Mundial é que a justiça constitucional passou a ter destaque no plano nacional de diversos países. Viu-se a importância do controle de constitucionalidade por um tribunal especializado, ou seja, um Tribunal Constitucional. Tal

\footnotetext{
${ }^{1}$ A autora é advogada, especialista em direito público, mestre em direito e doutoranda em urbanismo pelo PROURB/UFRJ Com ênfase nos programas de inclusão social na cidade, direito à cidade e gestão democrática da cidade.e-mail: paulalessacc@yahoo.com
} 
Tribunal teria como um de seus objetivos evitar deturpações do próprio sistema democrático, evitando legitimação de regimes populistas, através do enviesamento político de instrumentos democráticos e adequar todos os poderes aos pressupostos constitucionais de determinado país.

Surge, então, o Constitucionalismo que é uma teoria, talvez uma evolução do positivismo, que surge nos novos Estados Constitucionais contemporâneos. Neste novo sistema Sanchís (2005) destaca a concretude de um efetivo controle não só de constitucionalidade, mas de uma limitação e controle do poder. Exemplos de sistemas constitucionalistas são o sistema norte-americano de controle de constitucionalidade e as Constituições européias do pós-guerra. Os marcos essenciais deste sistema são: a importância dada aos valores mais que às normas; ponderação normativa, ao invés de subsunção, onipresença da Constituição em todas as leis ordinárias e onipotência judicial apoiada na Constituição, em detrimento da autonomia do legislador ordinário (ALEXY, 1994).

No século XXI e frente aos pressupostos dos Direitos Humanos Internacional, os Tribunais Constitucionais ganham maior importância, decidindo variada gama de questões, como exemplos de decisões têm-se: a manifestação da Suprema Corte Norte- Americana nas eleições presidenciais de 2000, que deu por legítima a eleição do presidente George Bush. No Canadá, a Corte se manifestou sobre a constitucionalidade de testes com mísseis norteamericanos em solo canadense; dentre outros inúmeros casos.

O presente artigo a partir da revisão bibliográfica levantada e da pesquisa à jurisprudência verifica que, no Brasil, igualmente, o papel do Supremo Tribunal Federal tem se destacado ao longo dos anos, seja pela importância crescente dada ao órgão em dirimir questões não solucionadas pelos outros poderes quando se manifesta sobre a constitucionalidade de lei, assim como, pela sua transparência, pois as questões além de publicadas, são discutidas e transmitidas ao vivo pela TV justiça. Igualmente é notório o intervencionismo do judiciário na política ou pela polêmica causada pelas suas decisões.

Como exemplos nacionais de decisões deste tribunal têm-se as questões da união homoafetiva, da fidelidade partidária, em que a vaga no congresso nacional pertence ao partido e não a pessoa eleita, demarcação das terras indígenas em Roraima, pesquisas em células tronco, dentre outras.

Observa-se a larga gama de questões que o Poder Judiciário, em particular, a Suprema Corte brasileira tem que se imiscuir. A problemática a ser dirimida pela Corte é 
muitas vezes técnica e exige muito mais que os conhecimentos limitados ao campo jurídico. Entretanto, o Supremo Tribunal Federal tem o dever de bem analisar tais questões e decidir, para isso a figura do Amicus Curiae.

Os exemplos aqui narrados demonstram a fluidez entre a política e a justiça no mundo contemporâneo. Observa-se neste cenário uma crescente judicialização de questões, que deveriam ser decididas por outras instâncias de poder. Levando-nos a questionar se o judiciário brasileiro ao ser tão demandado, talvez não o esteja sendo porque outras esferas de poder não são eficientes em suas atribuições originárias.

No Cenário de Pandemia COVID-19 percebe-se claramente esta judicialização em que por decisão do STF foi dado maiores poderes aos municípios e estados para decidir localmente. Assim como, o Poder Judiciário foi instado diversas vezes a se manifestar localmente contra decisões políticas realizadas, tais como: aberturas de escolas públicas e outros serviços, prioridade na vacinação, entre outros.

Esta judicialização envolve a transferência de poder para os juízes e tribunais. Assim, questiona-se: está o judiciário brasileiro legislando ou o controle de constitucionalidade e sua interpretação é um instrumento a suprimir lacunas deixadas por outros poderes, constituindose uma ferramenta útil para a democracia brasileira.

\section{HISTÓRICO DO CONTROLE DE CONSTITUCIONALIDADE ATRAVÉS DE TRIBUNAIS CONSTITUCIONAIS}

Após a Segunda Guerra Mundial, verificaram-se algumas distorções que poderia sofrer o Estado Democrático de Direito que se justificariam e se legitimariam através do modelo legalista adotado. Assim, surge a necessidade de um controle de constitucionalidade e de legalidade da norma, presentes na doutrina positivista, que seria mais justificado se exercido através de um Tribunal Constitucional.

O positivismo ainda dominante no pensamento jurídico da época justificava um Tribunal. Entretanto, o mundo saia de um modelo de Estado legislador e legalista e caminhava para um Estado Constitucionalista de Direito, tal Estado deveria ser o senhor da lei, mas não do direito.

Nesta nova concepção de Estado o que estava em xeque era que mesmo através dos poderes populares legitimamente constituídos não podia o Estado ditar o direito de uma 
nação. No modelo de Estado Constitucional passa a ser primordial o respeito de todos os seus organismos à lei, sendo esta uma garantia contra Estados totalitários

Sob esta nova ótica não podia mais o poder judiciário estar subjugado aos demais poderes, tinha que ter igualdade, devendo a jurisprudência também ser uma determinação, uma norma para o direito.

As decisões do Tribunal Constitucional da Alemanha, criado em 1951, ganharam enorme influência sobre a vida política. A jurisprudência deste Tribunal afetava diretamente a vida da nação alemã. Por vezes, o Tribunal se via no centro de discussões públicas provocadas por uma de suas decisões. A jurisprudência deste Tribunal abrangia a mais diversa gama de questões, tais como: a concessão de rádios e televisões, partidos políticos, o Tratado Fundamental entre as duas Alemanhas, dentre outras.

Para Kelsen (2007) a jurisdição constitucional deveria ser atribuição de um tribunal independente.

“Este (Tribunal Constitucional) central na medida em que, num processo litigioso, deve decidir sobre constitucionalidade de atos do Parlamento (especialmente leis) ou do governo (especialmente decretos) que tenham sido contestados, cassando tais atos em caso de sua inconstitucionalidade, e eventualmente julgando sobre a responsabilidade de certos órgãos colocados sob acusação." (KELSEN, 2007)

Para os defensores do constitucionalismo, o controle através de um tribunal é o modelo que permite maior transparência daqueles que exercem o poder, segundo Sanchís (2005). Com o agigantamento do Estado, com cada vez mais funções e intervenções, principalmente em meio econômico e a quantidade enorme de leis emanadas, cabe ao sistema constitucionalista verificar se tais normas estão de acordo com a constituição e se respeitam os princípios constitucionais e, no caso de haver conflito entre às normas ou a norma e um costume, ou moral local, cabe aos juízes a partir de uma valoração de princípios verificarem a validade daquela norma, não somente em seu aspecto formal, mas principalmente material com a Constituição. Encarnando assim, o mais efetivo controle de regulação e limitação do poder.

Para Kelsen (2007) o Tribunal Constitucional faria somente o papel de legislador negativo, destacando que a vantagem de tal tribunal é ser neutro, pois não participa do exercício do poder, mas somente de seu controle. 
A legitimidade de um Tribunal Constitucional está no fato de que ele foi escolhido por aquele que foi legitimamente eleito para nomear seus ministros e estes passaram pelo crivo de aprovação previsto na Constituição, logo são legítimos. Assim como, por serem juízes e assalariados, deveriam ser impelidos à neutralidade muito maior que qualquer outro poder.

\section{ANÁLISE DA CONSTITUCIONALIDADE DAS LEIS À LUZ DOS PRINCÍPIOS CONSTITUCIONAIS E SUPRANACIONAIS}

As leis questionadas nas Cortes Superiores são comparadas com as disposições da Lei Fundamental, para que se verifique a compatibilidade. A Lei Fundamental também abrange princípios contidos no texto constitucional e princípios derivados, tais quais: princípio da democracia, princípio federativo; princípio da fidelidade federativa, princípio do Estado de Direito, princípio da ordem democrática ou liberal e o princípio do Estado social.

Nos julgamentos constitucionais, os princípios fazem parte da constitucionalidade material, pois dão à Constituição uma unidade e um sistema de valores. Os princípios, segundo Bonavides, 2004 são instrumentos eficazes na hermenêutica constitucional, amparando a legitimidade e congruência do ordenamento jurídico.

"Sem princípios e valores, não se limita a autoridade dos governantes se isso acontece, não funciona a máquina do poder democrático e representativo, funciona, sim, a máquina de coação das autocracias". (BONAVIDES, 2004. P. 62)

No tocante ao Direito Suprapositivo como parâmetro de controle de constitucionalidade, os positivistas não reconhecem que o controle de constitucionalidade possa se basear em princípios que não estejam contidos no texto constitucional, mas somente aqueles contidos no texto da Constituição. No Brasil se admite o controle de constitucionalidade com base nos princípios explicitados no texto da Carta Magna, como também nos implícitos.

O texto constitucional alemão faz menção a princípios de direito suprapositivo, como a proteção da dignidade humana, igualdade e justiça material, incorporando tais princípios na ordem jurídica pátria. A favor da validade destes princípios como parâmetros de controle de constitucionalidade, Gilmar Ferreira Mendes (1996) destaca que estes são iminentes a qualquer ordem jurídica e tais princípios foram reconhecidos expressamente pela Lei 
Fundamental. Nesta linha de pensamento, poderia a Corte Constitucional alemã se valer do direito supranacional para aferição de constitucionalidade de lei, mas deveria se restringir somente aos casos fundamentais para a preservação do Estado de Direito.

O Tribunal Constitucional alemão entendeu que há possibilidade de uma norma constitucional originária ser inconstitucional e negar a esta a possibilidade significava coadunar com a idéia de um positivismo despido de valores. Deste modo, seria possível que no caso de notória e extremada contradição entre a lei e os parâmetros de justiça, o direito positivado tivesse que ceder lugar aos princípios supranacionais, de forma a evitar a formação de Estados totalitários.

A dificuldade de aferição de constitucionalidade das normas constitucionais primárias esbarra na dificuldade de se legitimar a atuação do Tribunal neste sentido, uma vez que os poderes que lhes são outorgados são criação do próprio constituinte, assim como ele mesmo. Para ser legítimo e exercer tal controle, seria o direito suprapositivo que lhe daria esta prerrogativa. Torna-se importante frisar que a definição dos princípios fundamentais do direito suprapositivo que deveriam servir de parâmetros de controle é de difícil seleção.

No âmbito da jurisdição constitucional os princípios podem desempenhar um papel extremamente perigoso, sobretudo ao pretender tomá-los como parâmetros para aferição da constitucionalidade da lei. Quando a Constituição recomenda ao legislador que atue em consonância com os princípios de "justiça", "liberdade", "equidade", "bons costumes", etc., se poderia vislumbrar nessas expressões diretivas para o conteúdo de leis futuras. Entretanto, isto levaria a um raciocínio de cisão errôneo, uma vez que tais diretivas somente se fazem presentes se se indica determinada direção, ou seja, se determinado critério objetivo é estabelecido na própria Constituição.

Essas disposições, por vezes, servem de adorno político da Constituição, confundemse facilmente no catálogo de direitos e liberdades fundamentais com outras normas que, efetivamente, definem o conteúdo de leis futuras; deste modo torna-se, por vezes, necessário que um Tribunal Constitucional seja convocado a decidir sobre a constitucionalidade de uma lei e até mesmo que venha a declarar sua inconstitucionalidade, porque se estaria diante de uma lei injusta, e a "justiça” é um principio constitucional devendo ser aplicado pela Corte.

\section{CONSTITUCIONALISMO JURÍDICO}


O grande diferencial entre o positivismo jurídico e o constitucionalismo é que aquele é uma concepção sobre o direito e este é um modelo de organização jurídica sobre o direito já existente ou que se quer construir. O positivismo sozinho não foi suficiente para solucionar as questões complexas do próprio sistema jurídico.

Neste século XXI, alguns conceitos típicos de Estado têm sido relativizados, como o da própria soberania no tocante aos direitos humanos e frente às novas tendências mundiais de globalização e regionalização, com a atuação cada vez mais marcante de Tribunais internacionais $^{2}$ e regionais ${ }^{3}$. Percebe-se um novo conceito de organização judiciária, que vem a ser o constitucionalismo, podendo ser este traduzido como um triunfo do próprio Estado Constitucional Democrático de Direito. O direito não se entende mais como um sistema fechado, autosuficiente, separado da moral, mas sim um sistema coerente e dinâmico.

Os princípios e a nova concepção de Estado Constitucional apregoam uma racionalidade material em que não se pode dissociar valores da norma positivada, valores estes expressos ou implícitos no texto constitucional, consolidando uma aproximação entre o direito e a moral, justificando uma jurisdição constitucional que contribua para os pressupostos da democracia.

"A Constituição encarna uma ordem de valores ou de unidade material. O papel desempenhado antes pelo direito natural em relação ao soberano, hoje desempenha a Constituição no tocante ao legislador". (KELSEN, 2007. p. 17)

No constitucionalismo jurídico a Constituição é a norma máxima do sistema, a ela devem estar submetidos todos os poderes: o executivo, o legislativo e o judiciário. Nenhum destes poderes está imune ou é autônomo à Constituição. O constitucionalismo dotou a ordem jurídica como sistema que permita interpretar, julgar e criar com respeito à Constituição e ao caso concreto.

O constitucionalismo não encerra o ordenamento em si mesmo, ele é uma ferramenta contra o totalitarismo, pois não dissocia o direito da moral. A moral está presente na forma de princípios. Princípios esses que não podem ser usados a esmo, mas que devem ser ponderados frente ao caso concreto analisado. Princípios que não são arbitrários, nem estão dentro da cabeça de um juiz singular, mas sim princípios que estão dentro do próprio ordenamento, em

\footnotetext{
${ }^{2}$ Ex: Tribunal Penal Internacional em Haya.

${ }^{3}$ Ex: Corte Interamericana de Direitos Humanos.
} 
sua Lei Máxima. Os princípios encerram a moral de um determinado povo ou nação e devem ser ponderados uns com os outros, ou frente à norma.

Deste modo, o constitucionalismo moderno permite que o ordenamento jurídico seja suprido com base em uma ponderação de princípios frente ao caso concreto apresentado, se comprometendo com a moral e os valores. Deste modo, a norma não vale tão somente porque foi escrita e obedeceu a um procedimento jurídico para se fazer valer. Neste sistema, pode ser o caso de ao se contrapor uma lei e um valor moral, da primeira perder, o que seria impensável em um pensamento positivista. Isto porque os valores e princípios que se ponderam com a norma válida têm força constitucional, eles representam a lei suprema tendo, assim, mais valor que a norma positivada.

No constitucionalismo, o legislador tem que moldar suas propostas aos ditames constitucionais que se adéquam inclusive aos ditames internacionais, aos acordos e tratados assinados, principalmente no tocante aos Direitos Humanos.

Igualmente, toda constituição, por mais rígida que seja, é dotada de dinamismo, que não obrigatoriamente necessitará reformar aquela constituição, mas que poderá através da ponderação, do escalonamento de princípios, da mudança de valores ao longo do tempo dotar a constituição de capacidade de adaptação ao momento moderno, sem a necessidade de alteração de seu texto constitucional.

\section{ATIVISMO JUDICIAL: POLÍTICA OU CONTROLE DE CONSTITUCIONALIDADE}

Observa-se que toda a Corte Constitucional, primeiramente, pelo modo de sua composição é uma corte política, pois é eleita ou escolhida por determinado poder, conforme ditado na Carta Constitucional do país. As questões que tal Corte analisa, uma vez decididas, pelo grau de importância e pelo espectro de abrangência geram repercussões políticas de modo inevitável. Entretanto, o que não pode acontecer é que a mais alta Corte do país se contamine por um viés ideológico, decidindo seus ministros politicamente, ou mesmo que juízes de primeira e de segunda instância, quando decidam de modo incidental sobre a constitucionalidade de leis, não o façam dotados das mais distintas ideologias.

Desta forma, faz-se importante uma jurisprudência constitucional e de um minimalismo judicial, para que seja dada a cada poder a sua função de direito. Um juiz deve se deter à coerência com a jurisprudência produzida pelos tribunais. Coadunar uma decisão à 
jurisprudência não significa perda de liberdade decisória, mas segurança jurídica, responsabilidade das decisões e não um arbítrio judicial.

Ao se constitucionalizar uma matéria significa transformar Política em Direito, pois ao se disciplinar uma norma constitucional ela se transforma em uma pretensão jurídica, portanto normas abertas constitucionais e não implementadas na prática, podem vir a ser demandadas no judiciário. Exemplos destas demandas na jurisprudência brasileira são diversas decisões no tocante ao direito genérico à saúde que originou uma série de interferências do Poder Judiciário em questões tocantes ao fornecimento de remédios essenciais a determinadas doenças.

A jurisdição constitucional que ganhou força no pós-Segunda Grande Guerra não pode ser confundida com ativismo judicial, tal postura faz com que o Poder Judiciário se imiscua em questões de modo proativo expandindo o alcance de sua decisão e politizando o órgão. O ativismo judicial acaba suprindo a ausência de um poder legislativo em que o povo não vê atendidas suas necessidades e direitos de forma efetiva.

O modo contrário do ativismo judicial seria a autocontenção judicial, conduta em que o poder judiciário procura reduzir a interferência de suas ações na de outros Poderes (BARROSO, 2009). Por essa linha de pensamento, o judiciário evita aplicar a Constituição a questões que não estejam no seu âmbito de atuação expressa, prevalecendo o pronunciamento do legislador ordinário; faz uso de critérios mais rígidos e conservadores para declarar a inconstitucionalidade de uma norma e abstém-se de interferir na definição de políticas públicas. Esta forma de atuação é muito razoável, uma vez que o judiciário não se destina a legislar, nem pode suprir de modo satisfatório a atuação de um órgão técnico. A autocontenção restringe o espaço de incidência da Constituição somente ao tocante e questões tipicamente políticas.

Barroso (2006) afirma que o Judiciário no Brasil optou claramente por uma postura ativista, em que se aplica a Constituição a questões não diretamente contempladas no seu texto e independentemente de manifestação do legislador, exemplifica com a decisão sobre fidelidade partidária, pois com esta decisão criou-se através de uma decisão judicial mais uma hipótese para perda do mandato, que se dará no caso da pessoa eleita se desfiliar do partido que a elegeu. Tal decisão se baseou em princípios constitucionais, como o da moralidade e o da impessoalidade. 
No tocante ao risco de politização do judiciário, um Tribunal Constitucional detém funções políticas. Entretanto, em um Estado pós-positivista, o direito se aproxima da ética, devendo uma decisão judiciária ser embasada com elementos técnicos do direito e sem voluntarismos jurídicos.

O Direito não se dissocia da política, na medida em que é ele uma criação política da vontade da maioria que se manifesta na Constituição; sua aplicação esta associada a realidade fática e temporal em que está inserido. Os próprios juízes estão inseridos na realidade em que apreciam, portanto por mais balizados que estejam suas decisões e dentro dos limites constitucionais vigentes, é impossível lhes retirar um aspecto político. Entretanto, este viés político pode ser tido como natural, uma vez que se trata de Tribunal Constitucional, mas a atenção tem que ser detida no tocante para que não se crie um modelo juriscentrico e elitista. Para que isto não ocorra o juiz deve agir dentro dos limites da estrita legalidade, jamais deixar intervir a pessoalidade em suas decisões; deve respeitar a razoabilidade das decisões tomadas pelo legislador.

O magistrado, apesar de não eleito, exerce um poder representativo, portanto suas decisões devem ser harmônicas ao sentimento social do que é justo. Na medida do possível, entendem-se os casos de decisões que deverão ser dadas de modo contramajoritário.

Nos últimos anos, o ativismo judicial e a judicialização têm sido traços marcantes no universo jurídico brasileiro. A judicialização é decorrente do modelo de Estado Constitucionalista e de seu controle através do Poder Judiciário, sendo uma vontade do constituinte tal controle. Por sua vez, o ativismo judicial expressa um modo proativo de o juiz interpretar à norma, em particular a Constituição, potencializando o sentido e o alcance das normas, indo por vezes além do legislador ordinário, podendo ser entendido como um mecanismo para contornar o processo político majoritário, mesmo que na tomada de decisão o juiz seja dotado de infinitas boas razões.

Há riscos que envolvem a judicialização e o ativismo judicial, são eles: a legitimidade democrática para tomada de decisões, pois os juízes não são eleitos, nem sua atividade se destina a este fim; a politização da justiça e a falta de capacidade do judiciário de analisar determinadas matérias.

"A Constituição é, precisamente, o documento que transforma o poder constituinte em poder constituído, isto é, Política em Direito. Essa interface entre dois mundos dá à interpretação constitucional uma 
inexorável dimensão política. Nada obstante isso, ela constitui tarefa jurídica.” (BARROSO, 2009. p. 345)

O grande questionamento enfrentado por um Tribunal Constitucional é se as suas decisões, por terem caráter político, estariam usurpando a função legislativa, criando modificações jurídicas que por suas implicações práticas se tornam regras.

Em resposta a tal questionamento, pode-se entender que o judiciário brasileiro, formado por servidores públicos qualificados e concursados, mas não eleitos, com funções previstas no texto constitucional, que em sua estrutura contém o Supremo Tribunal Federal e o Superior Tribunal de Justiça, o primeiro com a função de guardião da constituição, são legitimados na própria Carta Magna a realizar este controle de constitucionalidade de forma legítima.

Não estando desconexo à democracia, o fato do Tribunal Constitucional ser político, o caráter político intrínseco de suas decisões é manifesto. A forma de nomeação dos ministros, o teor da matéria que decidem, sua visibilidade tornam o Supremo Tribunal Federal eminente órgão político, mas ainda assim legítimo e contribuindo para a democracia.

Nas palavras de Kelsen (2007):

"Se fosse da natureza da jurisdição não ser política, então seria impossível uma jurisdição internacional, a decisão de controvérsias internacionais entre Estados. Todo conflito jurídico é na verdade um conflito de interesses ou de poder, e, portanto toda controvérsia jurídica é uma controvérsia política". (KELSEN, 2007. p. 251 e 252)

\section{MINIMALISMO NAS DECISÕES SOBRE CONSTITUCIONALIDADE}

Sunstein (1999) pontua que em todos os países que adotaram Cortes Constitucionais para exercerem o controle de constitucionalidade, observa-se um movimento pendular entre o ativismo e a contenção judicial. Tal fato pode ser explicado pela atuação dos outros dois poderes, o Executivo e o Legislativo.

“A expansão do Judiciário não deve desviar a atenção da real disfunção que aflige a democracia brasileira: a crise de representatividade, legitimidade e funcionalidade do Poder Legislativo. Precisamos de reforma política. E esta não pode ser feita por juízes."

(BARROSO, 2009. p. 346) 
No tocante ao Poder Legislativo, no caso brasileiro, o passar dos anos tem demonstrado o descrédito da população com tal poder e a sua omissão nos mais diversos assuntos, o que se traduz em uma crise de representatividade e legitimidade deste poder, tal fato é um incentivo à expansão do poder Judiciário, que através de suas decisões supre omissões legislativas em pontos essenciais.

Kelsen (2007) ressalta que caso se deseje diminuir o caráter discricionário nas decisões destes Tribunais Constitucionais o correto seria o texto constitucional restringir expressões generalistas, como "liberdade", "igualdade" e "justiça", o que não é factível, pois como bem pontua Gustavo Zagrebelsky o legislador é limitado, não pode a lei exaurir em seu texto todas as situações fáticas possíveis, assim expressões como "boa fé", "honra", "justo" estarão presentes em toda legislação constitucional e sua codificação, cabendo a análise ao caso concreto, pois de outro modo a jurisdição teria esvaziado a sua razão de existir, se restringindo a uma função mecanicista.

O Constituinte não tem como esgotar no texto constitucional todas as suas possibilidades. Ele deve deixar algumas aberturas, justamente para que a norma se adéqüe às novas realidades, estando o seu conteúdo sempre atualizado; assim, conceitos como igualdade, liberdade, dentre outros podem ter a opção de não estarem esmiuçados no texto constitucional.

Deste modo, ao longo do tempo, pode a Corte mudar de opinião ao longo do tempo, sem que seu novo posicionamento confronte o texto constitucional, mas o adequando a uma nova realidade prática, como exemplo, em 2011 o STF reconheceu as uniões estáveis homoafetivas.

A forma de pensar minimalista, então, se resume em interferir o menos possível e deixar que técnicos e os demais poderes executem o seu papel, mas não se omitir de decidir. Nesta linha de pensamento, constitui o minimalismo decisório quando a Corte Constitucional decide o mínimo necessário, ou seja, somente a questão trazida à baila, deixando questões marginais não decididas.

Tal atitude se justifica de modo a coibir uma usurpação de poder legislativo pelo poder judiciário, pois este último não está investido como formulador de leis e não teria legitimidade para tanto. Em um país onde as decisões das cortes superiores são vinculantes, como é o caso dos Estados Unidos esta questão é ainda mais marcante, pois a Corte se atendo ao mínimo que lhe é trazido à análise não cria precedentes vinculantes. 
O minimalismo traz como vantagens tornar o erro judiciário menos freqüente e menos danoso, assim como se abstém de causar intervenções que podem ter consequiências distorcidas, uma vez que não foram planejadas pelo Poder Público, como, por exemplo, o fornecimento obrigatório de determinados remédios e tratamentos de saúde pela rede pública, que pode beneficiar o autor da ação em prejuízo de uma coletividade.

Nos Estados Unidos, em que as decisões se valem de precedentes de cortes superiores o minimalismo é muito importante, entretanto no Brasil, onde também se adota o controle de constitucionalidade difuso, em que os juízes de primeiro grau têm poder de decisão não vinculado a decisões de Tribunais Superiores, o minimalismo torna-se muito importante, pois não permite um agigantamento do judiciário e nem uma usurpação de poder legislativo por parte deste.

As decisões emanadas pelo Poder Judiciário estão sujeitas a erros e o minimalismo das decisões se justifica, pois se a democracia estiver funcionando, os três poderes trabalhando em harmonia, não deve o processo político de escolhas e decisões ser interrompido por decisões do poder judiciário. Deste modo, o minimalismo prestigia a democracia, pois deixa questões complexas abertas que deverão ser de análise do legislador, ou do corpo técnico do poder executivo.

\section{CONCLUSÃO}

As objeções que se faz à crescente intervenção do Poder Judiciário são: os riscos para a legitimidade democrática do país, politização indevida do judiciário e os limites técnicos de compreensão da magnitude de suas decisões.

No tocante ao risco para a legitimidade democrática, pode-se argüir em defesa dos magistrados que estes apesar de não eleitos desempenham, inegavelmente, um poder político, inclusive o poder de invalidar atos dos outros dois poderes, seria um poder político, por vezes, contramajoritário.

Para se viver em um Estado Constitucional democrático é preciso conjugar o Estado de Direito como expressão da razão e o estado democrático como vontade do povo (soberania popular) e o Constitucionalismo como a limitação de todos os poderes para que coadunem com a Constituição Federal que é a expressão máxima da vontade popular. O texto constitucional também exerce o papel de proteger os valores e direitos fundamentais, sendo 
assim, mesmo que esses se choquem com a vontade da maioria, sendo o intérprete final da Constituição o Supremo Tribunal Federal.

A jurisdição constitucional, embasada nas normas positivadas na Constituição Federal e nos princípios constitucionais é uma garantia para a democracia. Deste modo, o Tribunal estará atuando legitimamente quando for capaz de adequar suas decisões ao texto constitucional.

O papel do judiciário na atualidade é dirimir divergências nas interpretações das normas, mas isto não legitima uma atitude arrogante, por parte deste poder, devendo o judiciário optar por não interferir sempre que vislumbre que outro poder ou órgão técnico possa corrigir o que está sendo pleiteado, devendo optar por uma autolimitação espontânea.

A Corte Suprema Brasileira é exemplo do alcance político de decisões por ela julgadas, como a discussão sobre o uso de células tronco embrionárias, a questão sobre fidelidade partidária e o reconhecimento às uniões homoafetivas. Tais decisões, apesar de polêmicas, indicam que a sociedade está demandando por uma resposta sobre elas e se existe o sentimento que o judiciário está se politizando de forma excessiva através de destas decisões, talvez esteja havendo falha em algum dos outros dois poderes, ou um excesso de normas por parte do poder executivo ou uma omissão do poder legislativo.

O debate de questões que envolvem princípios constitucionais pela Corte Constitucional Brasileira e pelo próprio Poder Judiciário, como um todo, contribui para que os demais poderes quebrem sua inércia, seja esta retratada na edição abusiva de medidas provisórias por parte do executivo, ou pelo vazio legislativo que domina a política brasileira da atualidade, constituindo a jurisdição constitucional um exercício em prol da democracia. 


\section{BIBLIOGRAFIA}

BARACHO, José Alfredo de Oliveira. Justiça Constitucional: garantia ou déficit da rigidez constitucional? In SAMPAIO, Adércio Leite (coord). Crise e Desafios da Constituição. Belo Horizonte: Del Rey, 2004. p. 77-136.

BARROSO, Luís Roberto. Fundamentos teóricos e filosóficos do novo direito constitucional brasileiro - pós modernidade, teoria crítica e pós-positivismo. In QUARESMA, Regina e OLIVEIRA, Maria Lúcia de Paula (coords). Direito Constitucional brasileiro: perspectivas e controvérsias. Rio de Janeiro: Forense, 2006. p. 27-66.

BARROSO, Luís Roberto. O controle de constitucionalidade no direito brasileiro: exposição sistemática da doutrina e análise crítica da jurisprudência. $4^{\mathrm{a}}$ ed. São Paulo: Saraiva, 2009.

BARROSO, Luís Roberto. Interpretação e aplicação da constituição: fundamentos de uma dogmática constitucional transformada. $7^{\text {a }}$ ed. São Paulo: Saraiva, 2009.

BOBBIO, Norberto. Liberalismo e Democracia. São Paulo: Brasiliense, 2005.

BOBBIO, Norberto. O positivismo jurídico: lições de filosofia do direito. São Paulo: Ícone, 2006.

BONAVIDES, Paulo. As quatro crises do Brasil constitucional. In SAMPAIO, Adércio Leite (coord). Crise e Desafios da Constituição. Belo Horizonte: Del Rey, 2004. p. 55-76.

CONSTANT, Henri Benjamin. Princípios Políticos Constitucionais. Rio de Janeiro: Liber Juris, 1989.

DALLARI, Pedro B. A. Constituição e Tratados Internacionais. São Paulo: Saraiva, 2003. p. $20-44$.

DUGUIT, Leon. Las transformaciones del derecho publico. Madrid: Francisco Beltran, 1917.

GUERRA FILHO, Willis Santiago. Jurisdição Constitucional no Brasil e tutela da ordem jurídica subjetiva. In QUARESMA, Regina e OLIVEIRA, Maria Lúcia de Paula (coords). Direito Constitucional brasileiro: perspectivas e controvérsias. Rio de Janeiro: Forense, 2006. p. 253-270.

HESSE, Konrad. A força normativa da constituição. Porto Alegre: Sergio Antonio Fabris Editor, 1991.

KELSEN, Hans. Jurisdição Constitucional. São Paulo: Martins Fontes, 2007. 
KELSEN, Hans. Teoria Pura do Direito. São Paulo: Martins Fontes, 2003.

MENDES, Gilmar Ferreira. Jurisdicao Constitucional. São Paulo: Saraiva, 1996.

MIRANDA, Jorge. Teoria do Estado e da Constituição. $2^{\mathrm{a}}$ ed. São Paulo: Forense, 2009.

MIRANDA, Pontes de. Comentários à Constituição de 1967. Tomo IV. Rio de Janeiro: Revista dos Tribunais, 1967.

SANCHÍS, Luis Prieto. Constitucionalismo y positivismo. Cidade do México: Fontamara, 2005.

SUSTEIN, Cass R. One Case at a Time: Judicial Minimalism on the Supreme Court. Cambridge, Massachusetts: Harvard University Press, 1999.

VIEIRA, José Ribas. Redefinindo a jurisdição constitucional e a sociedade de risco. In QUARESMA, Regina e OLIVEIRA, Maria Lúcia de Paula (coords). Direito Constitucional brasileiro: perspectivas e controvérsias. Rio de Janeiro: Forense, 2006. p. 271-300.

ZAGREBELSKY, Gustavo. El derecho dúctil. Madrid: Giulio Einaudi editores, 2009. 